\title{
A DESCENTRALIZAÇÃO DA EDUCAÇÃO BÁSICA PARA MUNICÍPIOS E ESTADOS: REALIDADES E CONTRADIÇÕES
}

\author{
THE DECENTRALIZATION OF BASIC EDUCATION FOR MUNICIPALITIES AND STATES: \\ REALITIES AND CONTRADICTIONS \\ LA DESCENTRALIZACIÓN DE LA EDUCACIÓN BÁSICA PARA MUNICIPIOS Y ESTADOS: \\ REALIDADES Y CONTRADICIONES
}

Eduardo Ferreira da Silva Caetano Universidade de Brasília E-mail: eduardofscaetano@gmail.com

\begin{abstract}
RESUMO
Na década de 1990, os governos Fernando Collor de Mello e Fernando Henrique Cardoso adotaram o discurso de controle econômico, eficiência e efetividade dos serviços públicos e modernização no país, impuseram o processo de descentralização como solução para repassar ações, programas ou obrigações do governo federal para os municípios e estados. Este artigo visa demonstrar que não ocorreu a descentralização (autonomia plena) e sim a desconcentração (autonomia limitada) no Brasil. Para tanto, o presente artigo elucida o sentido e as diferenças entre descentralização e desconcentração. Por fim, mostra que não ocorreu descentralização no Brasil, e sim, desconcentração, pois o Estado delega a execução, mas centraliza a normatização, regulação e o poder decisório.
\end{abstract}

PALAVRAS-CHAVE: Descentralização. Desconcentração. Educação básica.

\begin{abstract}
In the 1990s, the governments Fernando Collor de Mello and Fernando Henrique Cardoso adopted the discourse of economic control, efficiency and effectiveness of public services and modernization in the country, imposed the decentralization process as a solution to transfer actions, programs or obligations of the federal government for municipalities and states. This article aims to demonstrate that decentralization (full autonomy) has not occurred, but rather the deconcentration (limited autonomy) in Brazil. For this, this article elucidates the meaning and the differences between decentralization and deconcentration. Finally, it shows that there was no decentralization in Brazil, but rather, deconcentration, because the State delegates the execution, but centralizes the regulation, regulation and decisionmaking power.
\end{abstract}

KEYWORDS: Decentralization. Deconcentration. Basic Education.

\section{RESUMEN}

En la década de 1990, los gobiernos Fernando Collor de Mello y Fernando Henrique Cardoso adoptaron el discurso de control económico, eficiencia y efectividad de los servicios públicos y modernización en el país, impusieron el proceso de descentralización como solución para repasar acciones, programas u obligaciones del gobierno federal para los municipios y estados. Este artículo pretende demostrar que no ocurrió la descentralización (autonomía plena) y sí la desconcentración (autonomía limitada) en Brasil. Para ello, el presente artículo eluciona el sentido y las diferencias entre descentralización y desconcentración. Por último, muestra que no ocurrió descentralización en Brasil, sino desconcentración, pues el Estado delega la ejecución, pero centraliza la normatización, regulación y el poder decisorio.

PALABRAS-CLAVE: Descentralización. Desconcentración. Educación básica.

\section{INTRODUÇÃO}

O parágrafo $1^{\circ}$, do artigo 208, da Constituição Federal de 1988 normatiza como obrigação do Estado a oferta da educação básica obrigatória, gratuita e como direito público subjetivo. Na década 
de 1990, o Estado brasileiro, governado pelos presidentes Fernando Collor ${ }^{1}$ e Fernando Henrique $\mathrm{Cardoso}^{2}$, que se ajustaram aos preceitos neoliberais, flexibilizaram diversas obrigações constitucionais, entre elas a de ofertar e financiar a educação básica por meio da descentralização. Este trabalho defende, assim como outros estudiosos, que a descentralização da educação básica impossibilita a implementação de um sistema nacional de educação; cria a ideia de eficiência, qualidade, agilidade e transparência na prestação de serviços públicos pela transferência de responsabilidades, e ainda, descentraliza para os governos estaduais e municipais, detentores de receitas fiscais e tributárias menores, a atribuição de investir em educação pública. (CURY, 2010; SAVIANI, 2010; KANG, 2010; SOUZA \& FARIA, 2004)

Nesse sentido, o presente artigo sobre a descentralização praticada no Brasil problematiza as seguintes situações: Como conceituar descentralização nas perspectivas dos movimentos sociais e do governo? Como os governos de Fernando Collor e Fernando Henrique Cardoso promoveram a descentralização? Como a descentralização atinge a realidade da educação básica brasileira? Como correlacionar descentralização com a qualidade do ensino oferecido pelos estados e municípios? Como relacionar a descentralização ao pagamento de baixos salários efetuados aos professores da educação básica brasileira?

Essa discussão propõe um recorte com três objetivos: primeiro, conceitua descentralização diferenciando o seu sentido de desconcentração, centralização e recentralização. Busca ainda a contextualização histórica focada na década de 1990, evidencia como os governos Collor e FHC utilizaram a descentralização em suas administrações; no segundo, problematiza as consequências da descentralização para a realidade da educação básica brasileira (financiamento e responsabilidade) e discute como a descentralização provoca efeitos no pagamento do piso salarial dos professores. Em terceiro, identifica e analisa como a descentralização da educação, para os governos estaduais e municipais, atinge a qualidade do ensino oferecido.

\section{REFERENCIAL TEÓRICO}

Para este estudo, utilizou-se a análise documental como meio para a obtenção de dados. Para a perspectiva metodológica fez-se a escolha pelos aspectos qualitativos do contexto pesquisado. Assumiu-se o mundo como uma realidade material e histórica, em que o homem pode conhecê-la e

\footnotetext{
${ }^{1}$ Fernando Affonso Collor de Mello (Rio de Janeiro, 12 de agosto de 1949) é um político, jornalista, economista, empresário e escritor brasileiro. Foi prefeito de Maceió de 1979 a 1982, governador de Alagoas de 1987 a 1989, deputado federal de 1982 a 1986, 32 presidente do Brasil, de 1990 a 1992, e senador por Alagoas de 2007 até a atualidade. Foi o presidente mais jovem da história do Brasil (na época com 40 anos de idade), o primeiro presidente eleito por voto direto do povo, após o Regime Militar (1964/1985) e um dos presidentes depostos por um processo de impeachment no país. Seu governo foi marcado pela implementação do Plano Collor e a abertura do mercado nacional às importações e pelo início de um programa nacional de desestatização. É comumente chamado pelo por seu sobrenome COLLOR.

${ }^{2}$ Fernando Henrique Cardoso (Rio de Janeiro, 18 de junho de 1931) é um sociólogo, cientista político, filósofo, professor universitário, escritor e político brasileiro. Professor emérito da Universidade de São Paulo, lecionou também no exterior, notadamente na Universidade de Paris. Foi funcionário da Comissão Econômica para a América Latina e o Caribe, membro do Centro Brasileiro de Análise e Planejamento, senador da República (1983 a 1992) ministro das Relações Exteriores (1992), ministro da Fazenda (1993 e 1994) e o $1^{\circ}$ presidente do Brasil a ser eleito para $2^{\circ}$ mandatos consecutivos (de 1995 a 1998 e de 1999 a 2002). É conhecido pelo acrônimo de seu nome completo FHC.
} 
transformá-la, por isso adotou-se o método da concepção materialista da realidade e da concreticidade e a categoria contradição. (CURY, 2002; CAETANO, 2015, 2017)

\subsection{Descentralização: seus significados e aplicação na educação básica brasileira}

O processo de descentralização ocorrido no Brasil, na década de 1990, teve amplitude em diversas políticas sociais de atuação do Estado, em especial, na educação. O parágrafo $2^{\circ}$, do artigo 211, da Constituição Federal de 1988, normatizou que os municípios atuarão prioritariamente no ensino fundamental e na educação infantil. Já o parágrafo $3^{\circ}$, do mesmo artigo, esclarece que os estados e o Distrito Federal devem atuar prioritariamente também no ensino fundamental e no ensino médio. Essa imposição, expressa na maior Lei do país, representou a regularização para a aplicação da descentralização da educação.

Assim, a descentralização da educação básica brasileira tem o seu modo de funcionamento sob a esfera da autonomia dos entes federativos, obedecendo ao princípio da colaboração recíproca, fixada pela Constituição Federal de 1988 e massivamente executada pelos governos da década de 1990. O vocábulo descentralização é definida por Houaiss (2001) como ato ou efeito oposto à acumulação dos poderes no governo central.

A ação do Estado de transferir aos demais entes subnacionais a competência constitucional de oferecer a educação básica tornou-se realidade devido à junção da União, Estados, Distrito Federal e Municípios autônomos entre si, que se associaram para formar o Estado brasileiro originando o federalismo. Para Hesse (1998), federalismo é entendido como um princípio político fundamental, que tem como objetivo unificar totalidades políticas diferenciadas em um conjunto de regras comuns, postas de modo a efetivar uma colaboração comum entre seus componentes.

A Constituição de 1988 determina a adoção do federalismo cooperativo sob a denominação de regime articulado de colaboração recíproca, descentralizada, com funções privativas, comuns e concorrentes entre os entes federativos. É justamente pela descentralização que a União repassa aos estados e municípios a obrigatoriedade de ofertar e financiar a educação básica e ainda arcar com o pagamento do piso salarial dos professores.

Por isso, descentralização é definida como uma repartição de poderes ou responsabilidades entre as coletividades locais. Entende-se como sendo o repasse ou divisão de reponsabilidades ou poderes entre o poder central e os poderes subnacionais (Estados, Distrito Federal e Municípios). A unidade simboliza responsabilidade centralizada do Estado (União) que quando dividido em partes é distribuído, sendo essa distribuição a descentralização.

Os governos neoliberais exercem a descentralização em nível de execução e não o repasse na plenitude dos aspectos políticos-econômicos-sociais. Assim, quando repassam a obrigação de fazer aos entes delegados, na maioria das vezes, continuam detendo os recursos orçamentários-financeiros, centralizadores do poder de regulação e fiscalizadores das ações das políticas públicas encarregadas. Contrários a essa forma de governar, os movimentos sociais defendem a colaboração recíproca como transferência plena de competência, autonomia, financiamento, controle e participação social para os entes federados. 


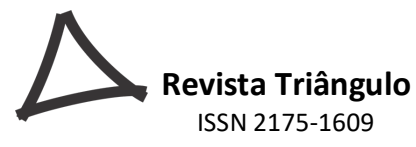

ISSN 2175-1609

Para Cury (2002), as políticas de colaboração recíproca no atual pacto federativo significam um repasse de responsabilidades dos escalões nacionais para os subnacionais. Nesse sentido, o Estado brasileiro divide suas responsabilidades com o intuito de minimizar as suas atribuições quanto à oferta dos direitos sociais. Para tanto, utiliza-se o processo de descentralização como sinônimo de progresso e modernização do país.

Além de repassar a atribuição de ofertar a educação básica, o Governo Federal diminuiu seus encargos. Nesse sentido, o estudioso Kulgemas (1999) destaca que o pragmatismo do governo federal de descentralizar se deu pela busca de reduzir seus encargos para disponibilizar os direitos sociais. Os processos descentralizadores no setor público frequentemente têm como característica o repasse do poder de execução do nível nacional aos níveis subnacionais. Corrobora com isso, o pesquisador Tobar (1991), que afirma que os processos descentralizados constituem a transferência de autoridade no planejamento e na tomada de decisões.

Nota-se que a descentralização apresenta dimensão política e econômica. Sendo a política a possibilidade de construir uma sociedade mais justa e democrática, e quanto à dimensão econômica, nota Arretche (1996), é um desdobramento da visão política, sendo um instrumento capaz de apaziguar as disparidades financeiras para fortalecer a sociedade civil frente a um estado excessivamente centralizador e regulador.

Para o Governo Federal, a descentralização representa sinônimo de modernização gerencial, possibilidade de amenização das desigualdades, otimização dos gastos públicos, dinamização e qualificação da prestação dos serviços públicos. Nessa linha, Melo (1997) defende esse entendimento de que a descentralização é considerada um instrumento de modernização gerencial de gestão pública, pela crença das possibilidades de promover a eficácia e a eficiência dos serviços transferidos. Eficácia significando atingir os objetivos planejados e a eficiência no sentido de que a atividade administrativa repassada seja exercida com presteza e obtenção de resultados positivos ao atendimento das necessidades da sociedade.

O sentido de descentralização realizada pelo Estado, para Azevedo (2002), significa a transferências de competências da esfera central de poder para os locais, respaldada em orientações neoliberais é defendida como meio de otimização dos gastos públicos e redução do Estado às funções mínimas. Este pensamento mostra que o discurso do governo central, de maior eficiência e efetividade para aplicação dos recursos financeiros na educação, é uma manobra para descentralizar a sua atribuição constitucional aos estados e municípios brasileiros.

O processo de descentralização, ocorrido desde a Constituição Federal de 1988, pregou também a transferência intencional de funções e responsabilidades para a comunidade através do envolvimento privado no processo educacional brasileiro. Nessa linha, Krawczyk (2005, p. 813) afirma que a descentralização brasileira é a privatização das escolas em "pequenas doses", é a retração do Estado como mantenedor da educação pública. Por isso, governos neoliberais promovem a colaboração de diferentes setores da sociedade como Amigo na Escola, Responsabilidade Social, Empresa Cidadã, ou programas Adote uma Escola, Parceria Empresa Escola Pública e o movimento Todos pela Educação.

$\mathrm{Na}$ realidade, a descentralização tornou-se uma maneira conveniente do Estado (União) repassar suas responsabilidades sem necessariamente compensar financeiramente os entes

\begin{tabular}{l|l|l|l|l|l} 
C Revista Triângulo & Uberaba, Minas Gerais & v.12 & n.1 & p. 85-102 & 2019
\end{tabular}




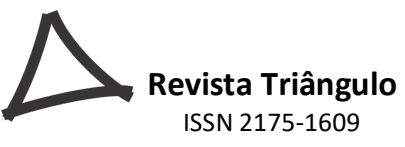

ISSN 2175-1609

subnacionais, mesmo considerando o fato de que estes, em sua maioria, são os menores possuidores de recursos financeiros. Destaca sobre isso o educador Jesus (2007), que a descentralização não visa à transferência dos recursos econômicos e, sim, o repasse da responsabilidade do direito da educação a outros entes.

Ao analisar essa realidade, constata-se que a maioria dos governos brasileiros utilizam a descentralização como meio de reduzir as obrigações do Estado e diminuir as obrigações políticoadministrativas do Estado. Este trabalho defende que o pagamento do piso dos educadores não é uma realidade, porque o Estado apropriou-se da palavra descentralização e a resignificou com o sentido e prática de desconcentração. Descentralização em seu sentido pleno significa transferência de responsabilidades, respeito à autonomia e repasse financeiro correspondente as obrigações transferidas. O Estado transferiu o dever de ofertar educação obrigatória e pagamento do piso salarial dos professores da educação básica, só que não repassou recursos financeiros, tributários e fiscais que pudessem significar descentralização aos entes subnacionais.

Para os movimentos sociais, Movimento Nacional de Meninos e Meninas de Rua - MNMMR e ao Fórum do Maciço Central do Morro da Cruz, descentralizar consiste em repasse total das atribuições e obrigações juntamente com os aspectos financeiros, políticos e sociais e não apenas o repasse de execução. Para Rivas (1991), a descentralização propriamente dita não se trata apenas de delegação de tarefas, mas autonomia de poder de decisão sobre aspectos como financiamento, elaboração do currículo local, administração e gestão educacional para os entes locais. Nota-se a ampliação do sentido de delegação e execução para participação, elaboração, administração e gestão por parte dos governos subnacionais.

Reforçando o conceito de descentralização, Martins (2001) define descentralização como a transferência de poder integral do nível do governo central para as subnacionais. Assim, os entes descentralizados se responsabilizarão pela adoção e gestão integral de determinados recursos com o intuito de viabilizar a execução política, administrativa e financeira, combinando a participação da sociedade civil em todas as etapas do processo decisório.

O Estado transfere a execução, mas não os recursos financeiros fiscais, tributários e de gestão plena para os municípios. A normatização, regulação e os recursos financeiros continuam centralizados no governo central que repassa, via descentralização, somente a execução da oferta do ensino e não a transferência de recursos, organização e regulamentação. Por isso, a descentralização brasileira está mais para desconcentração do que para descentralização. Conforme defendido por Oliveira (2005), a descentralização em seu sentido pleno significa autonomia nas dimensões pedagógica, administrativa e de gestão financeira, como promotora do aumento da participação dos usuários na gestão e no controle das políticas públicas e no aumento da eficácia do processo.

2.2 O sentido de desconcentração e sua aplicação na transferência de responsabilidades do Estado

A descentralização teve seu sentido original modificado ao ser apropriada e resignificada pelos governos neoliberais, com isso as ações descentralizadas realizadas pelo Estado brasileiro estão 


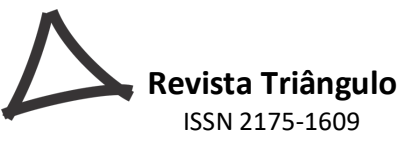

ISSN 2175-1609

mais para o sentido de desconcentração. Esta tem como característica a delegação somente da execução de ações de políticas públicas ou programas e não propicia autonomia integral ao ente local.

Segundo o estudioso Casassus (1989), desconcentração reflete processos cujo objetivo é o de assegurar a eficácia do poder central, assim, entende-se a desconcentração como a delegação de determinadas funções a entidades regionais ou locais que dependem diretamente do outorgante. Isso evidencia que as delegações, via desconcentração, ocorrem pela autoridade outorgante que transfere apenas algumas funções ou obrigações com o objetivo de diminuir as responsabilidades do poder central. Os entes desconcentrados ficam vinculados às regulações e fiscalizações do poder central outorgante.

Ampliando o significado de desconcentração, Martins et tal (2001) entende como transparência de gestão operacional, não política, de determinados objetivos definidos e coordenados em nível central a outra intragovernamental. Enquanto a descentralização pressupõe a capacidade de definição política dos princípios objetivos e metas a serem alcançados no âmbito a ela vinculado.

Desconcentração e descentralização diferem-se, pois a primeira repassa ou delega ação, função ou programa que se vinculam ao ente central, a segunda não é transferência integral de âmbito político, econômico e de autonomia. Assim, na educação a descentralização pregada e implementada pelo Estado brasileiro não ocorre em seu sentido pleno, não possibilita a delegação financeira, política e administrativa e, por isso, está mais para desconcentração.

A desconcentração tem como característica manter o Órgão Central como centralizador. O Estado brasileiro, por exemplo, mantém concentrado para si a maioria dos recursos financeiros, tributários e fiscais. O Estado (Órgão Central) transfere a obrigação de pagamento do piso dos educadores aos entes, diminui a responsabilidade do ente central e os entes ficam vinculados às regulações e fiscalizações do poder outorgante e não transfere os recursos em sua plenitude para os entes decentralizados, ao contrário, repassa o que lhe é conveniente. Estas ações comprovam que há desconcentração e não descentralização.

\subsection{A relação do federalismo e do gerencialismo para a descentralização da educação básica}

O federalismo origina-se da palavra do latim faedus, a qual significa contrato. É um sistema político em que Estados, Distrito Federal e Municípios, sendo independentes, formam um todo que valida um governo central e federal que governam sobre todos os demais entes. No sistema federalista, os estados que o integram mantém a autonomia. Nesse sentido, Arretche (2002) acentua que federação diz respeito à distribuição da autoridade política e fiscal dos Estados nacionais. Em um sistema federalista, os impostos recebidos pelos estados são repassados para o Governo Federal, que então os redistribui de maneira proporcionalmente igualitária entre as unidades federativas.

O federalismo está ligado ao gerencialismo. Este termo é utilizado por estudiosos do campo educacional para referir-se à adoção de ferramentas da gestão empresarial na educação, em que a participação está atrelada ao comprometimento, ao controle e a descentralização presentes nas concepções empresariais e difundidas por meio de políticas públicas na década de 1990 e nos anos 2000. Na ótica do gerencialismo, a administração pública orienta suas atividades de modo a garantir controle, eficiência e competitividade.

\begin{tabular}{l|l|l|l|r} 
(C) Revista Triângulo & Uberaba, Minas Gerais & v.12 & n.1 & p. 85 - 102
\end{tabular} 
Nessa mesma linha de entendimento, Vieira (1997) assevera que o gerencialismo visa gerenciar a educação segundo padrões econômicos de eficiência e eficácia, mas, sobretudo, obedientes à análises sociais e políticas de financiamento. O responsável por gerenciar a eficiência e eficácia da educação no país é a União, que se utiliza do pacto federativo descentralizado compartilhado para repassar a obrigação de ofertar educação básica aos municípios e aos estados.

Os defensores do gerencialismo sustentam que sua aplicação plena e eficiente melhora as ações e decisões do governo federal liberal. Segundo Bresser Pereira (1998), a reforma gerencial objetiva aumentar a eficiência e a efetividade dos órgãos e agências do Estado, melhorar a qualidade das decisões estratégicas do governo e sua burocracia e assegurar o caráter democrático da administração pública. Há uma difusão da ideia de que o setor privado é mais eficiente do que o público, portanto, as suas diretrizes de organização se aplicadas ao setor público racionalizam os serviços e reduzem o gasto público.

No campo da educação, o modelo de gestão gerencial, pautado na descentralização administrativa dos macro e microssistemas, se apresenta como fórmula prática para resolver os problemas crônicos da educação pública no Brasil. Esse modelo de gestão passa a ser incluído na agenda política como proposta inovadora e modernizadora da gestão educativa do governo para garantir o sucesso escolar, tendo influência direta nos projetos políticos dos governos subnacionais.

O federalismo permitiu a descentralização de responsabilidades constitucionais como a oferta e o financiamento da educação básica. Com a descentralização executada no sentido de desconcentração provocou as desigualdades tributaria, fiscal e educacional no país, pois o governo federal centralizou a maioria dos recursos para si e distribuiu aos outros entes subnacionais a minoria desses recursos, tendo o Estado característica de centralizador.

\subsection{O conceito de centralização na política pública educacional brasileira}

A centralização significa poder de dominação nas mãos de raros detentores, que se efetiva quando poucos tomam a decisão pela maioria, sejam nos campos dos: recursos humanos, financeiros, definição de linhas, planos e programas. Nesta não ocorre a delegação total ou parcial das atribuições para os outros entes subnacionais.

De acordo com Oliveira (1999), centralização indica que a definição de rumos da política educacional em nível central expressa a vontade de um pequeno grupo político que possui o poder de decisão e delegação de planos, programas ou recursos financeiros. Esse entendimento esclarece que as decisões, normas, regulações e fiscalizações são definidas pelo órgão central detentor de poder e de responsabilidades a si vinculadas.

Outro conceito é o de Bastos (1975), o qual define centralização como um instrumento que tem como alvo tudo dominar. Sendo estas decisões ou determinações tomadas próximas ao topo hierárquico, visa garantir, postergar ou dominar com poder tudo que a si vinculada. Se ao realizar a descentralização o Órgão Central interpretar que esta ameasse a permanência ou a amplitude do poder vinculado, o Estado ou Órgão Central recentraliza a responsabilidade a si vinculada. Segundo a pesquisadora Ferreira (2009), recentralização significa a ação de tornar ou voltar a centralizar ou uma 
nova centralização, seja política ou administrativa. O Órgão Central age buscando atingir seu objetivo principal de garantir e manter a continuidade do seu poder político ou administrativo.

Recentralização, para Souza (1999), significa retomada do papel central da União na federação. O Estado detém discricionariedade para requerer a obrigação delegada segundo suas necessidades, sejam: políticas, econômicas ou financeiras. Os conceitos de colaboração recíproca, desconcentração, centralização e retomada da centralização são pertinentes para analisar o processo de descentralização promovido na educação básica do país na década de 1990 .

\section{MATERIAIS}

A década de 1990 foi uma das mais marcantes para a história do Brasil e caracterizou-se pelo começo da redemocratização e sua consolidação. Em 15 de março 1990, tomou posse Fernando Collor de Mello, primeiro presidente eleito depois do Movimento Diretas-Já. Naquele momento, o Brasil viveu uma crise por causa do endividamento externo e pelos ajustes macroeconômicos adotados que buscavam um plano de estabilização econômica.

Ao assumir a presidência, esse governo tinha algumas promessas de campanha como a modernização do país, combate à corrupção e, sobretudo, a moralização da administração pública. Para conseguir esta modernização, este governo buscou e defendeu legitimar a redução de custos e a descentralização de políticas públicas do Estado como meio de propiciar eficácia e eficiência na aplicação dos recursos públicos bem como a dos serviços públicos prestados.

Para tanto, o governo Collor adota como discurso e prática a descentralização e a redução dos gastos do Estado. Tem como base, no contexto mundial, as reuniões organizadas pela Organização das Nações Unidas para a Educação, a Ciência e a Cultura-UNESCO, o Banco Mundial e o Consenso de Washington ${ }^{3}$ que recomendavam um processo de reformas educacionais na América Latina e também no Brasil, diminuição dos gastos públicos, privatizações das estatais, disciplina fiscal, etc. É por meio da Declaração Mundial sobre Educação para Todos, de Jomtien ${ }^{4}$ (UNESCO, 1990), que estes organismos defendem a implantação da descentralização de ações do Estado no campo educacional.

\footnotetext{
${ }^{3}$ Consenso de Washington é um conjunto de medidas - que se compõe de dez regras básicas - formulado em novembro de 1989 por economistas de instituições financeiras situadas em Washington D.C., como o FMI, o Banco Mundial e o Departamento do Tesouro dos Estados Unidos, fundamentadas num texto do economista John Williamson, do International Institute for Economy, e que se tornou a política oficial do Fundo Monetário Internacional em 1990, quando passou a ser receitado para promover o ajustamento macroeconômico dos países em desenvolvimento que passavam por dificuldades.

${ }^{4}$ Foi uma Conferência Mundial sobre Educação para Todos realizada entre 5 a 9 de março de 1990 em Jomtien na Tailândia, organizada pela UNESCO, reuniu cerca de 1500 participantes, entre eles os delegados de 150 países incluindo especialistas em educação e autoridades nacionais. Além de contar com representantes de organismos intergovernamentais e não governamentais que examinaram em 48 mesasredondas e em sessão plenária aspectos sobre a educação. Os textos dos documentos foram revisados e aprovados na sessão plenária de encerramento da Conferência em 9 de março de 1990. Ficou conhecida como a Declaração Mundial sobre Educação para Todos. Denominada Declaração de Jomtien.
} 
A estratégia adotada para a superação da crise vivida no Brasil, na década de 1990, foi a reforma do Estado por meio da diminuição de sua atuação, isto é, com a "privatização e redução do tamanho do Estado, se reduzia o gasto público e eliminaria o déficit público, os grandes vilões da inflação". (SANTOS, 2002, p. 99)

Com intuito de o país entrar na era da modernidade, Fernando Collor de Mello assumiu a política neoliberal, estabelecendo reformas no Estado, as quais propiciaram a exclusão de direitos às classes mais pobres da população, pois buscava instituir o modelo do Estado Mínimo, que não garantia os direitos sociais. A redução em oferecer os direitos sociais não propiciou garantia de direitos para as classes trabalhadoras, mas serviu para criar mecanismos de garantia e ganhos para o capital especulativo, conforme assevera Peroni (2000):

O Estado é mínimo apenas para as políticas sociais, pois, na realidade, o Estado é máximo para o capital, porque além de ser chamado a regular as atividades do capital corporativo, no interesse da nação, tem, ainda, de criar um 'bom clima de negócios' para atrair o capital financeiro transnacional e conter [por meios distintos dos controles de câmbio] a fuga de capital. (PERONI, 2000, p. 55)

A descentralização defendida pelo governo Collor ficou mais no discurso do que propriamente na sua aplicação, pois as ações do Estado estavam todas centralizadas. O governo Collor ficou marcado pela instabilidade, o confisco de poupanças e os negócios obscuros entre governo e Paulo Cesar Farias, empresário e tesoureiro de sua campanha. O movimento Cara Pintada pressiona pelo impeachment do então presidente Fernando Collor. O Congresso Nacional, acatando a aclamação da população, aprova o impeachment e o vice-presidente, Itamar Franco, assume o governo. Nessa época, há transformações e efervescências locais e mundiais, marcantes para esse período e para o futuro do país.

Em 1993, no contexto internacional ocorre a posse do democrata Bill Clinton ${ }^{5}$ como presidente dos Estados Unidos da América que tinha como uma de suas principais bandeiras a redução das barreiras do Tratado Norte-Americano de Livre Comércio-NAFTA. No Brasil, nesse mesmo ano, foi realizado o plebiscito sobre sistema de governo, o qual venceu a República Presidencialista. Também nesse ano, foi lançada a Declaração de Nova Delhi ${ }^{6}$ (1993), administrada por burocratas capitalistas ávidos por ganhos e amplitude de alcance do capitalismo, que recomendava ajuste estrutural total em países que não tivessem ainda reduzido as ações do Estado. Nessa linha, indaga, Silva Junior (2002), que os compromissos assumidos por meio de tais documentos internacionais, com as agências internacionais, aqui com destaque para as de ordem financeira, realizar-se-á sob a orientação de um ajuste estrutural no país.

\footnotetext{
${ }^{5}$ William Jefferson Clinton (Hope, Arkansas, 19 de Agosto de 1946) mais conhecido como Bill Clinton, é um político dos Estados Unidos que foi o $42^{\circ}$ presidente do país, por dois mandatos, entre 1993 e 2001. Antes de servir como presidente, Clinton foi governador do estado do Arkansas por dois mandatos. Tomou posse aos 46 anos, ele foi o terceiro presidente mais jovem na data em que tomou posse. Ele tomou posse no final da Guerra Fria e foi o primeiro presidente da geração baby boomer.

${ }^{6}$ Declaração de Nova Delhi sobre Educação para Todos aprovado por aclamação em Nova Delhi em 16 de dezembro de 1993. Estabeleceu metas para atender às necessidades básicas de aprendizagem de todos os nossos povos tornando universal a educação básica e ampliando as oportunidades de aprendizagem para crianças, jovens e adultos.
}

\begin{tabular}{l|l|l|l|l|l|} 
(C) Revista Triângulo & Uberaba, Minas Gerais & v.12 & n.1 & p. 85 - 102 & 2019
\end{tabular}


As recomendações da UNESCO e do Banco Mundial ao sugerir a reforma do Estado reafirmam os interesses do capital. O Brasil, signatário dessa declaração, cria o Plano Decenal de Educação para Todos (1993-2003), considerando suas recomendações. Silva Júnior (2002) afirma que na esfera educacional, esse Plano decenal de Educação para Todos é a expressão brasileira do movimento planetário realizado pela UNESCO, BIRD/Banco Mundial, e assumido como orientador das políticas públicas para a educação.

No governo seguinte, de Itamar Franco, em 1994, o país experimentou: estabilidade econômica, crescimento, diminuição e controle da inflação com o Plano Real de 1994, que igualava a paridade da moeda com o dólar. O Ministro da Fazenda, criador do Real, Fernando Henrique Cardoso, foi o responsável por tal proeza. Nesse mesmo ano, o NAFTA entra em funcionamento e o povo brasileiro elege Fernando Henrique Cardoso como presidente, que transforma o Estado brasileiro aberto ao capital especulativo estrangeiro, consolida as privatizações e solidifica a redução de obrigação do Estado em disponibilizar direitos em aspecto social.

A eleição de Fernando Henrique Cardoso, para o período de 1995 a 1998, continuou a política iniciada no governo Collor e Itamar Franco com vistas a modificações significativas na concepção de democracia e do papel da sociedade brasileira. Seu governo também foi caracterizado por medidas fundamentadas nos princípios neoliberais de privatizações de empresas estatais. Esse governo foi decisivo para a concretude da descentralização, a Reforma do Estado no Brasil, a substituição da administração pública burocrática pela administração gerencial, a qualidade da educação e o processo de ampla privatização de estatais brasileiras.

A reforma proposta por Luiz Carlos Bresser Gonçalves Pereira, em 1995, e executada no Ministério da Administração Federal e da Reforma do Estado - MARE, buscou a instituição da eficácia, efetividade e eficiência da aplicação dos recursos públicos e aumentou a capacidade administrativa de governar por retirar do Estado o dever de fornecer direitos sociais à sociedade. Limitou, assim, a ação do Estado àquelas funções que o governo lhe atribuísse como sendo próprias; transferindo da União para os estados e municípios as ações de caráter local e regional. Conforme acentuado pelo próprio governo, no Plano Diretor da Reforma do Aparelho do Estado brasileiro, 1995, que defendeu:

O movimento de descentralização da atual política educacional, no qual é descentralizado o financiamento e centralizado o controle, é parte da proposta de redefinição do papel do Estado, o que pode ser constatado no Plano Diretor da Reforma do Aparelho do Estado. (BRASIL, 1995, p. 4)

No que se refere à gestão pública ocorreu a descentralização da obrigatoriedade constitucional de ofertar a educação básica e financiar o ensino fundamental para os municípios, centralizou os recursos financeiros e recentralizou a normatização e a regulação para oferta de educação no Brasil.

O ministro da Administração Federal e Reforma do Estado, Bresser Pereira (1997), define dois objetivos para a implantação da descentralização, inclusive da educação em curto prazo, facilitar o ajuste fiscal, particularmente nos estados e municípios; e, em médio prazo, tornar mais eficiente e moderna a administração pública, voltando-a para o atendimento dos cidadãos. 


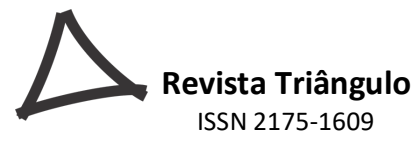

O Estado, na era de Fernando Henrique Cardoso, desconcentrou programas, descentralizou políticas, concentrou e gerenciou riquezas conforme realizou o ajuste e desestruturou os organismos de planejamento, pesquisa e fomento tecnológico. A sociedade e suas expressões organizativas não ficaram paralisadas. Entre uma alternativa e uma possibilidade de intervenção, foram instituídos processos de participação especialmente na esfera municipal, novos formatos de gestão com as agências de regulação e controle, foram reposicionadas políticas e projetos, a exemplo do Estatuto da Criança e do Adolescente, da Lei do Consumidor, do Conselho de Educação, entre outros.

Para o governo Fernando Henrique Cardoso, o repasse da execução dos serviços públicos ou obrigações constitucionais eram fundamentais. Para tanto, defendeu-se o poder de normatização e regulação centralizado "descentralização para o setor público não estatal da execução de serviços que não envolvem o exercício do poder de Estado, mas devem ser subsidiados pelo Estado" (BRASIL, 1995, p. 12). O governo tem os recursos financeiros, fiscais e tributários como uma atividade exclusiva do Estado, mas prega a execução descentralizada como participação popular, autonomia dos entes subnacionais e como meio para qualificar os serviços públicos.

Para Hölfling (2001), no que tange a educação, "os neoliberais não defendem a responsabilidade do Estado em relação ao oferecimento de educação pública a todo cidadão, em termos universalizastes, de maneira padronizada". A educação, nesse contexto, serve ao Estado capitalista para a formação do consenso, e de acordo com Falleiros (2005, pg. 219), "as estratégias educacionais mais do que nunca ganham importância vital na difusão dos conteúdos, habilidades e valores ligados a esse modelo de sociabilidade". O Estado neoliberal toma como objetivo central a volatividade do ganho do capital mesmo que tenha de reduzir ou retirar os direitos sociais da sociedade civil, por isso, a maioria dos governos neoliberais criam ou modificam leis afim de materializar em suas políticas a retração do Estado como mantenedor da educação pública. (KRAWCZYK,2015)

Isso ficou evidenciado pelo Artigo 211, da Constituição Federal de 1988, que efetivou a descentralização da educação como lei, em 1996. A descentralização no campo educacional ganhou força com a Lei no 9.424, de 24 de dezembro de 1996, a qual definiu a criação do Fundo de Manutenção e Desenvolvimento do Ensino Fundamental e de Valorização do Magistério (FUNDEF) ${ }^{7}$

\footnotetext{
${ }^{7}$ Fundo de Manutenção e Desenvolvimento do Ensino Fundamental e de Valorização do Magistério (FUNDEF) foi implantado, nacionalmente, em $1^{\circ}$ de janeiro de 1998, quando passou a vigorar a nova sistemática de redistribuição dos recursos destinados ao Ensino Fundamental. Este é caracterizado como fundo de natureza contábil, com tratamento idêntico ao Fundo de Participação dos Estados e ao Fundo de Participação dos Municípios, dada a automaticidade nos repasses de seus recursos aos Estados e Municípios, de acordo com coeficientes de distribuição estabelecidos e publicados previamente. As receitas e despesas, por sua vez, deverão estar previstas no orçamento, e a execução contabilizada de forma específica. A maior inovação do FUNDEF consiste na mudança da estrutura de financiamento do Ensino Fundamental no país, ao subvincular a esse nível de ensino uma parcela dos recursos constitucionalmente destinados à Educação. A Constituição de 1988 vincula $25 \%$ das receitas dos Estados e Municípios à Educação. Com a Emenda Constitucional n ${ }^{\circ}$ 14/96, 60\% desses recursos ficam reservados ao Ensino Fundamental. Além disso, introduz novos critérios de distribuição e utilização de 15\% dos principais impostos de Estados e Municípios, promovendo a sua partilha de recursos entre o Governo Estadual e seus municípios, de acordo com o número de alunos atendidos em cada rede de ensino. DOURADO, Luís Fernando; OLIVEIRA, João Ferreira de; SANTOS, Catarina de Almeida Santos. A qualidade da educação: conceitos e definições. Brasília: Instituto Nacional de Estudos e Pesquisas Educacionais Anísio Teixeira, 2007.
} 
e a Lei $n^{\circ} 9.394$ que criou a nova Lei de Diretrizes e Bases da Educação-LDB ${ }^{8}$. Estes dois instrumentos viabilizaram o governo de Fernando Henrique Cardoso, na década de 1990, descentralizar aos municípios a obrigação de oferecer o ensino fundamental. Os municípios com status de autonomia dos estados aceitaram a descentralização com a expectativa de cumprimento, por parte do governo Fernando Henrique Cardoso, do sistema de colaboração regimentado pelas novas leis.

A normatização, regulação e os recursos financeiros continuam centralizados no governo central que repassa, via descentralização, somente a execução da oferta do ensino e não a transferência de recursos orçamentários-financeiros, organização e regulamentação. Por isso, a descentralização brasileira está mais para desconcentração do que para descentralização. Conforme defendido por Oliveira (2005), a descentralização, em seu sentido pleno, significa autonomia nas dimensões pedagógica, administrativa e de gestão financeira, como promotora do aumento da participação dos usuários na gestão e no controle das políticas públicas e no aumento da eficácia do processo decisório no interior dos sistemas educativos, ou melhor, na ampla participação da sociedade nas ações de políticas públicas implantadas pelo Estado.

Segundo Peroni (2003), a descentralização da educação começa com a transferência de encargos e deveres do governo federal para os estados e municípios envolvendo diferentes níveis de estadualização de programas e projetos e de municipalização do ensino fundamental, no qual passam a exigir da escola novos papéis. Com a estratégia política de descentralização para o ensino fundamental, os municípios passam a ter responsabilidade do Plano Nacional de Alimentação Escolar e o Programa de Manutenção e Desenvolvimento do Ensino Fundamental.

Assim, o Governo Federal centraliza o controle e descentraliza a obrigação de ofertar a educação básica, sobretudo através do Fundef e do repasse de dinheiro direto para as escolas. A centralização e o controle do sistema se dá pela avaliação dos resultados do sistema educacional e de exames padronizados para todos os níveis de ensino.

Segundo o Instituto Brasileiro de Geografia e Estatística-IBGE (2013), o Brasil tem 5.570 municípios, estes entes, em sua maioria, recebem poucos recursos transferidos da União que são insuficientes para suprir o cumprimento das obrigações e direitos sociais repassados pela descentralização. O Estado em âmbito educacional descentralizou o ensino fundamental, uma das etapas mais abrangentes do ensino, para os municípios detentores de poucos recursos financeiros, fiscais e tributários. Com isso segundo Puccinelli (2010), os municípios têm poucos recursos financeiros, tributários e fiscais para investir na educação básica oferecida à sociedade.

O processo de descentralização executado no país propiciou uma grande concentração de tributos a cargo da União, significou também maior arrecadação de recursos financeiros e menores responsabilidades político-administrativas por parte da esfera federal, ao contrário dos demais entes que ficaram com menor carga tributária e maiores responsabilidades político-administrativas. Isto evidencia que não houve uma descentralização de competência tributária na mesma intensidade, desta

\footnotetext{
${ }^{8}$ A Lei de Diretrizes e Bases-LDB é a lei orgânica e geral da educação brasileira. Dita as diretrizes e as bases da organização do sistema educacional. Segundo o ex-ministro Paulo Renato Souza que ao lado do então presidente Fernando Henrique Cardoso sancionou a LDB. Esta não é detalhista, ela dá muita liberdade para as escolas, para os sistemas de ensino dos municípios e dos estados, fixando normas gerais.

\begin{tabular}{l|l|l|l|l|l|l} 
(C) Revista Triângulo & Uberaba, Minas Gerais & v.12 & n.1 & p. 85-102 & 2019
\end{tabular}
}


forma, fica comprovado que a descentralização é exercida como uma ressignificação de desconcentração, pois esta tem o sentido de repassar as competências, mas mantém os estados e municípios dependentes do governo federal.

\subsection{A municipalização da educação e suas consequências para a educação básica}

O princípio da descentralização político-administrativa foi definido pela Constituição de 1988, preconizando a autonomia dos municípios e a localização dos serviços públicos na esfera municipal, próximos dos cidadãos e de seus problemas. Sim, municipalização foi uma estratégia adotada no Brasil que reconhece o Município como principal responsável pela oferta dos direitos públicos de sua população. Municipalizar é transferir para as cidades a responsabilidade, a execução, planejamento e as ações dos serviços prestados em seu território.

A política de realizar e executar a descentralização da educação para os municípios não se mostra preocupada com a qualidade e aspectos pedagógicos, pelo contrário foca na administração pública e na diminuição da participação do Estado em proporcionar direitos sociais a seu povo. $\mathrm{O}$ pesquisador Souza (2006) diz:

Pode-se concluir que a opção do poder público pela descentralização, nos moldes em que se apresenta atualmente, está mais vinculada a uma dada concepção de administração da educação pública, a partir de uma racionalidade mais política do que pedagógica ou mesmo financeira, uma vez que, para a constituição/manutenção das condições de qualidade, o investimento financeiro não seria tão grande e o retorno pedagógico poderia ser compensador do esforço e maior. (SOUZA, 2006, p. 265)

Nessa linha, percebe-se que para muitos governos brasileiros neoliberais, a descentralização da educação está mais para a diminuição de recursos orçamentários-financeiros do Estado para a aplicação na educação, do que de fato uma ação para qualificar o ensino da educação básica brasileira. Mas, como se pode definir uma educação de qualidade para a sociedade?

Segundo Ferreira (2009), qualidade é uma maneira de ser, boa ou má, de uma coisa. Superioridade, excelência em qualquer coisa: preferir à qualidade a quantidade. Como conjunto de propriedades, atributos e condições inerentes a um objeto e que são capazes de distingui-lo de outros similares, classificando-o como igual, melhor ou pior; ou, então, como base em um padrão de referência.

Uma educação de qualidade, ou melhor, uma escola eficaz é resultado de uma construção de sujeitos engajados nos aspectos pedagógico, técnico e político do processo educativo, em que pesem, muitas vezes, as condições objetivas de ensino, as desigualdades socioeconômicas e culturais dos alunos, a desvalorização profissional e a possibilidade limitada de atualização permanente dos profissionais da educação. Isso significa dizer que não só os fatores e os insumos indispensáveis sejam determinantes, mas que os trabalhadores em educação (juntamente com os alunos e pais) são participantes ativos para a produção de uma escola de qualidade.

\begin{tabular}{l|l|l|l|l|l} 
(C) Revista Triângulo & Uberaba, Minas Gerais & v.12 & n.1 & p. 85-102 & 2019
\end{tabular}


Ainda, segundo o Boletim da UNESCO (2003), qualidade da educação é tida como a relação entre os recursos materiais e humanos, bem como a partir da relação que ocorre na escola e na sala de aula, ou seja, os processos de ensino aprendizagem, os currículos, as expectativas de aprendizagem com relação à aprendizagem das crianças, etc. Percebe-se que a qualidade pode ser definida a partir dos resultados educativos, representados pelo desempenho do aluno.

Para o educador Cury (2010), qualidade advém do latim qualitas, mas cuja procedência mais funda é a de poiótês, do grego, e que significa um título definidor de uma categorização ou classificação. De certo modo, qualidade está no campo de um atributo distintivo de um bem que passa a se apresentar com uma característica particular além da comum. Por vezes, essa distinção costuma ser assinalada como uma adjetivação, caso de qualidade social ou qualidade total.

\section{ANÁLISE DOS DADOS E RESULTADOS}

Este estudo defende a descentralização em sua plenitude, no sentido de que estados e municípios, além da atribuição de fazer, recebam também o gerenciamento dos recursos financeiros. Pois, esses entes subnacionais, pela proximidade e mais contato com as escolas e professores, têm condições de conhecer melhor as suas realidades e necessidades e, assim, aplicar de maneira mais precisa os recursos públicos.

O estudo realizado pelo pesquisador Caetano (2015), na Rede Municipal de Ensino de Unaí, com 48, dentre os 240 professores, do $1^{\circ}$ ao $5^{\circ}$ ano fundamental, utilizando a perspectiva metodológica analítica, interpretativa e qualitativa dos dados interpretados no método da concepção materialista e dialética da realidade, constatou que a descentralização tem propiciado desvalorização e precariedade nas condições de trabalho dos profissionais da educação, participantes do estudo. A pesquisa de Caetano (2015) revelou ainda, que os elementos que desvalorizam os profissionais em educação, da Rede Municipal de Unaí, são: para 51\%, baixos salários, $18 \%$ apontam falta de respeito com o professor, $11 \%$ afirmam falta de condições de trabalho, 11\% opinam falta de compromisso dos governantes e para 9\% falta de plano de carreira (CAETANO, 2015).

Esse estudo comprovou que a municipalização da educação não valoriza os professores, não propicia condições adequadas para o trabalho dos profissionais da educação, mas realça a falta de comprometimento dos governantes com a educação. A descentralização da educação do governo federal para os demais entes não propiciou mais recursos e nem autonomia para os entes municipais e estaduais, ao contrário tem contribuído para a manutenção histórica de precarização da educação.

(CAETANO, 2017)

\section{CONSIDERAÇÕES FINAIS}




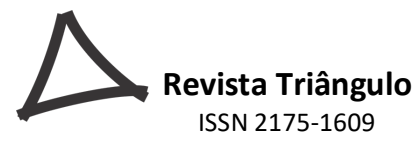

A descentralização executada no Estado brasileiro não representa poder decisório, autonomia e exercício de participação da sociedade civil na elaboração das ações de políticas públicas exercidas nos governos locais. Ao contrário, a municipalização da educação imposta e implantada nos municípios do país, durante a década de 1990, pelos governos neoliberais, Fernando Collor e Fernando Henrique Cardoso, significou a implementação da desconcentração.

Tais governos com o discurso de eficiência, eficácia e efetividade como forma de propiciar crescimento da economia, controle da hiperinflação e ainda possibilidade de melhora da qualidade dos serviços públicos prestados a sociedade, ressignificaram a palavra descentralização defendida por diversos movimentos sociais, para o sentido de desconcentração, a fim de atender aos propósitos do Estado. (MARTINS et tal, 2015)

Não ocorre descentralização no Brasil, e sim, desconcentração, pois o Estado delega a execução, mas centraliza a normatização, regulação e o poder decisório. Nesse sentido, a descentralização executada propicia a recentralização que permite ao poder da União, como Órgão Central, de retomar atividades, ações ou obrigações delegadas de volta para si. A descentralização almejada refere-se à delegação ou repasse de atribuição ou ação social, poder decisório, participação da sociedade civil, autonomia da gestão financeira, política e administrativa a qual propicie ao ente subnacional liberdade e condições para gerir, decidir, implementar e executar as obrigações delegadas pelo ato descentralizado.

Defendido por Souza (2003), descentralização é uma estratégia potencialmente capaz de facilitar o exercício da experiência democrática, por considerar o financiamento e a gestão da educação municipal como faces de uma mesma moeda. A municipalização da educação, no Brasil, banalizou a qualidade do ensino oferecido na maioria das escolas brasileiras. Os municípios, limitados de recursos fiscais e tributários, não possuem condições financeiras para aplicar em educação.

O resgate histórico, da década de 1990, é fundamental no tempo presente para a discussão e compreensão do processo de descentralização da educação, que na verdade está mais para desconcentração, pois a maioria dos governos neoliberais ao realizar a colaboração recíproca relativizam as características socioeconômicas da população, diferenças culturais, condições financeiras, tributárias e fiscais das cidades. O Estado repassa as competências, mas mantêm os estados e municípios dependentes de recursos orçamentários-financeiros, controle e normatização ao Órgão Central, a saber, a União.

Em suma, ao observar as manifestações sociais, de junho de 2013, na qual a maioria da sociedade reivindicou educação básica de qualidade como direito e realidade nas escolas públicas brasileiras, permite finalizar que o processo de descentralização da educação básica aos estados e municipios, no Brasil, é sim uma desconcentração, pois não consegue, em sua plenitude, o sentido prometido pelos governos liberais de eficiência, eficácia, efetividade e qualidade ao ofertar um ensino de alto padrão aos cidadãos brasileiros.

\section{REFERÊNCIAS}

ARRETCHE, M. Mitos da descentralização mais democracia e eficiência nas políticas públicas? Campinas, SP: RBCS, 1996.

\begin{tabular}{l|l|l|l|l|l} 
¡( Revista Triângulo & Uberaba, Minas Gerais & v.12 & n.1 & p. 85-102 & 2019
\end{tabular}


AZEVEDO, J. Implicações da nova lógica de ação do Estado para a educação municipal. Campinas, SP: Educação e Sociedade, v. 23, n. 80, p. 49-71, set. 2002.

BASTOS, A. A província: estudo sobre a descentralização no Brasil. São Paulo, SP: Nacional, 1975.

BANCO MUNDIAL. Educação Municipal no Brasil. Recursos, incentivos e resultados. New York, 2003.

BRASIL. Constituição da República Federativa do Brasil. São Paulo, SP: Imprensa Oficial do Estado, 1988.

BRESSER PEREIRA, L. C. Exposição no Senado sobre a reforma da administração pública. Brasília, DF: Cadernos MARE da Reforma do Estado, 1997.

CAETANO, E. F. S. Política de valorização profissional dos professores do $1^{\circ}$ ao $5^{\circ}$ ano de Unaí: A Lei do Piso. 2015, 184 p. Dissertação (Mestrado em Educação) - Faculdade de Educação, Universidade de Brasília, Brasília, 2015.

CAETANO, E. F. S. Os Ordenados e a Baixa Remuneração dos Professores das Primeiras Letras em Minas Gerais. Porto Alegre, FINEDUCA - Revista de Financiamento da Educação, v. 7, n. 10, p. 1-17, nov.2017.

CASASSUS, J. Descentralización y desconcentración de los sistemas educativos em América Latina: fundamentos y dimensiones críticas. Santiago, Chile: mímeo, 1989.

CASASSUS, J. Tarefas da educação. Campinas, SP: Autores Associados, 1995.

CURY, C. R. A Educação Básica no Brasil. Campinas, SP: Educ. Soc.; vol. 23, n. 80, p. 168-200, set. 2002.

CURY, C. R. Os desafios da construção de um sistema nacional de educação. In: CONAE-2010. Brasília, DF: Coletânea de textos da Conae, 2010.

FALLEIROS, I. Parâmetros Curriculares Nacionais para a educação básica e a construção de uma nova cidadania. In: NEVES, L. M. W. (Org.). A Nova pedagogia Hegemonia: estratégias do capital para educar o consenso. São Paulo, SP: Xamã, p. 209-235, 2005,

FERNANDES, J. Licitação: centralização ou descentralização? Brasília, DF: Correio Braziliense Suplemento do Direito \& Justiça, 1999.

FERREIRA, A. B. Novo dicionário Aurélio da língua portuguesa. Curitiba, PR: Ed. Positivo, 2009.

FURTADO, L. R. Um novo conceito em análise de obras públicas com relação à Lei de Responsabilidade Fiscal. Palestra proferida na SEAERJ. Rio de Janeiro, RJ: setembro de 2002. 


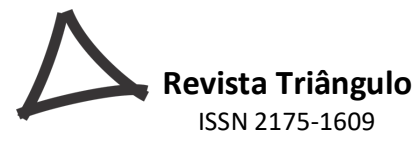

HESSE, K. Elementos de Direito Constitucional da República Federal da Alemanha. Porto Alegre, RS: Sergio Antônio Fabris, 1998.

HÖLfLING, E. Estado e Políticas (Públicas) sociais. Campinas, SP: Cadernos CEDES, 2001. HOUAISS, A.; VILlAR, M. Dicionário Houaiss da Língua Portuguesa. Rio de Janeiro, RJ: Objetiva, 2001.

IBGE. Atlas do Espaço Rural Brasileiro. Rio de Janeiro, RJ: 2013.

JESUS. W. F. "Despesa Sagrada": estudo sobre a vinculação constitucional de verbas a educação nas Constituições Brasileiras de 1934 e 1946. Brasília, Dissertação (Mestrado em Educação) Universidade Católica de Brasília, Brasília, 2007.

KANG, T. Descentralização Comparada na Educação: Brasil e Estados Unidos em Perspectiva Histórica. São Paulo, SP: FIPE, 2010.

KULGEMAS, E.; SOLA, L. "Descentralização federativa e reforma do Estado". Caxambu, RS: Trabalho apresentado no XXIII Encontro da ANPOCS, 1999.

KRAWCZYK, N. R. Políticas de Regulação e Mercantilização da Educação: socialização para uma nova cidadania? Campinas, SP: Educação e Sociedade, vol. 26, n. 92, p. 799-819, 2005.

MARTINS, A.; SANTOS, A. O financiamento da municipalização do ensino no município de São Paulo. In: GIUBILEI, S. (org.) - Descentralização, Municipalização e Políticas Educativas. Campinas, SP: Ed. Alínea, 2001.

MARTINS, A. S.; NEVES, L. M. W.; MELO, A. A. S. et al. Educação Básica: tragédia anunciada? São Paulo: Xamã, 2015.

MELO, M.; FALLEIROS, I. Reforma da aparelhagem estatal: novas estratégias de legitimação social. In: NEVES, L. M. W. (Org.). A Nova Pedagogia Hegemonia: estratégias do capital para educar o consenso. São Paulo, SP: Xamã, p. 175-192, 2005.

OLIVEIRA, R. Política educacional: impasses e alternativas. São Paulo, SP: Autêntica, 1999.

UNESCO. Declaração Mundial sobre Educação Para Todos (Conferência de Jomtien). Tailândia: UNESCO, 1990.

UNESCO. A Declaração de Nova Delhi sobre Educação Para Todos. Nova Delhi, Índia: Unesco, 1993.

PERONI, V. O Estado Brasileiro e a Política Educacional dos Anos 90. In: ANUÁrIO GT ESTADO E POLÍTICA EDUCACIONAL POLÍTICAS, GESTÃO E FINANCIAMENTO DA EDUCAÇÃO, 2002. Anais... Goiânia, GO: GEV, p. 51-68, 2000.

PERONI, V. Política Educacional e Papel do Estado: no Brasil dos anos 1990. São Paulo, SP: Xamã, 2003.

\begin{tabular}{l|l|l|l|l|l|} 
¡ Revista Triângulo & Uberaba, Minas Gerais & v.12 & n.1 & p. 85 - 102 & 2019 \\
\hline
\end{tabular}




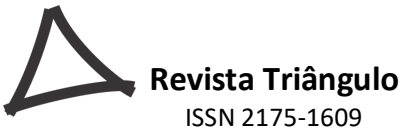

PUCCINELLI, F.; SLOMSKI, V. Um estudo do investimento público em educação básica no Brasil e do desempenho dos alunos em avaliações nacionais por Unidade Federativa no período de 1998 a 2007. In: Congresso de Iniciação Científica em Contabilidade, 2010, São Paulo. Anais... São Paulo, SP: USP, 2010.

RESTON, J. O Município para Candidatos. Rio de Janeiro, RJ: IBAM, 2000.

RIVAS, R. Política de descentralización en la educación basica y media en América Latina: Estado del Arte. Santiago, Chile: UNESCO/REDUC, 1991.

SANTOS, K. Construção Multicultural: Reflexões sobre políticas alternativas para o ensino de língua estrangeira. 2002. Tese (Doutorado em Letras) - Faculdade de Filosofia, Letras e Ciências Humanas, Universidade de São Paulo. São Paulo, SP: USP, 2002.

SAVIANI, D. Sistema de educação: subsídios para a conferência nacional de educação. In: CONAE-2010. Brasília, DF: Coletânea de textos da Conae, p. 61-71, 2010.

SILVA JUNIOR, J. Reforma do Estado e da Educação no Brasil de FHC. São Paulo, SP: Xamã, 2002.

SOUZA, C.; CARVALHO, I. Reforma do Estado, descentralização e desigualdades. São Paulo, SP: Lua Nova, 1999.

SOUZA, D.; FARIA, L. Reforma do Estado, descentralização e municipalização do ensino no Brasil: a gestão política dos sistemas públicos de ensino pós-LDB 9.394/96. In: CONGRESO DE LA ASOCIACIÓN LATINO AMERICANA DE SOCIOLOGÍA. Santiago, Chile: ALAS, 2003.

SOUZA, Â. O financiamento da educação na escola: análise dos recursos disponíveis em 13 escolas públicas no estado do Paraná. In: GOUVEIA, A.; TAVARES, T. (Org.). Conversas sobre o financiamento da educação no Brasil. Curitiba, PR: Ed. da UFPR, p. 249-267, 2006.

SPINK, P. Descentralização: Luto ou luta? Poder local: governo e cidadania. Rio Janeiro, RJ: FGV, 1993.

TOBAR, F. O conceito de descentralização: usos e abusos. São Paulo, SP: Atlas,1991.

\begin{tabular}{|l|r|}
\hline & Recebido em: 7 Fev. 2018 \\
\hline & Aprovado em: 18 Abr. 2019 \\
\hline
\end{tabular}

